\title{
Antibiotic prophylaxis and reflux: critical review and assessment
} Bernarda Viteri Baquerizo ${ }^{1}$ and Craig A. Peters ${ }^{2 *}$

\author{
Addresses: ${ }^{1}$ Maimonides Medical Center, 4802 Tenth Avenue, Brooklyn, NY 11219, USA; ${ }^{2}$ Sheikh Zayed Institute for Pediatric Surgical Innovation, \\ Children's National Medical Center, 111 Michigan Avenue, NW, Washington, DC 20010, USA \\ *Corresponding author: Craig A. Peters (crpeters@childrensnational.org) \\ FI000Prime Reports 2014, 6:104 (doi:10.12703/P6-104) \\ All Fl000Prime Reports articles are distributed under the terms of the Creative Commons Attribution-Non Commercial License \\ (http://creativecommons.org/licenses/by-nc/3.0/legalcode), which permits non-commercial use, distribution, and reproduction in any medium, \\ provided the original work is properly cited. \\ The electronic version of this article is the complete one and can be found at: http://f1000.com/prime/reports/m/6/104
}

\begin{abstract}
The use of continuous antibiotic prophylaxis (CAP) was critical in the evolution of vesicoureteral reflux (VUR) from a condition in which surgery was the standard of treatment to its becoming a medically managed condition. The efficacy of antibiotic prophylaxis in the management of VUR has been challenged in recent years, and significant confusion exists as to its clinical value. This review summarizes the critical factors in the history, use, and investigation of antibiotic prophylaxis in VUR. This review provides suggestions for assessing the potential clinical utility of prophylaxis.
\end{abstract}

\section{History and Background}

With the recognition of the relationship between renal scarring, urinary tract infection (UTI), and VUR, the clinical use of prophylactic antibiotics emerged in the early 1970 s. This was largely the result of the work of Normand and Smellie, who had shown a reduction in the incidence of UTI in children with VUR on CAP [1]. As a clinical strategy, CAP offered an alternative to surgical correction of VUR and became the recommendation of the American Urological Association (AUA) guideline in 1997 [2]. It is useful to review the data on CAP to understand its influence on the guidelines of VUR and UTI evaluation and management, recognizing its critical role in VUR management.

The original reports by Normand and Smellie were of patients with long histories of recurrent UTI, many of whom had renal injury (based on intravenous pyelogram data in most) and VUR. Use of trimethoprim was seen to alter the UTI rate significantly in most. Importantly, the approach of Normand and Smellie to these patients included rigorous management of voiding dysfunction as well as using CAP. Interestingly, the UTI rate was different among those with and without renal scarring, suggesting a different risk for these different groups [3].

Academic debate centered on whether the medical approach with CAP or the surgical approach offered a better long-term outcome in terms of reducing the incidence of acute infection and renal scarring. Three large clinical trials evaluated this question and demonstrated no clear advantage for medical or surgical treatment [4-6]. With increasing recognition of the potential importance of VUR, and the assumed need for early prevention of infection and scarring, more children were diagnosed with VUR, including those identified through sibling screening and evaluation of those with prenatal hydronephrosis [7]. Increasingly aggressive imaging for the child with UTI emerged, and the VUR population demographic shifted. Fewer patients with scars were being identified, and some had never experienced UTI. To attempt to prevent renal scarring from the recurrence of UTI, CAP became widely used. Eventually, concerns regarding the risks of CAP, including antibiotic resistance and the burden of daily medication, prompted the consideration of discontinuing antibiotic before reflux resolution $[8,9]$ or never using antibiotics in some. Many of these children were reported to have good outcomes, and the overall value of CAP was called into question.

Several larger prospective randomized studies demonstrated no benefit from CAP [10-13]. At the same time, endoscopic therapy with injectable bulking agents was evolving as an alternative to open surgery and was being 
offered in place of a trial on CAP [14]. As a result, the value of CAP in any child with VUR has been called into question and, with that, the value of identifying VUR. New guidelines have set stringent criteria for evaluating VUR with invasive imaging (such as voiding cystourethrogram, or VCUG) $[15,16]$. Clinically, this has created much confusion for parents, pediatricians, and family practitioners as well as specialists.

\section{Recent studies of continuous antibiotic prophylaxis}

The principal challenges to the use of CAP in VUR today include concerns regarding lack of demonstrated efficacy of CAP in children with VUR, evidence of limited compliance with medication use when placed on CAP, and the development of antibiotic-resistant organisms.

Several large, multicenter trials of the efficacy of CAP for VUR have been published in the last 6 years with varying outcomes. Table 1 summarizes these studies and highlights the differences in entry criteria and population characteristics. Studies showing no benefit to CAP often included patients with a single UTI, low grades of VUR, and very little renal damage (when assessed) and have relatively short follow-up. The means of diagnosing UTI in some included "bag" specimens, which may have produced artifactual high rates of apparent UTI. Similarly, many of the boys included were not circumcised, or circumcision status was unknown, yet this may contribute to UTI risk.

The study by Craig and colleagues [17], demonstrated a significant benefit to antibiotic prophylaxis, although the effect was considered "small" or "intermediate" by some, and this study also includes children with and without VUR (as well as a large number who never underwent VCUG). In contrast, the Swedish Reflux Trial (SRT) included children with higher grades of VUR (III and IV), younger age, and a significant incidence of renal injury based on dimercaptosuccinic acid (DMSA) scanning. It also included a "run-in" period where children, who had been diagnosed before 1 year of age, were maintained on CAP until age 1 year and who still had VUR on follow-up VCUG $[18,19]$. Many children had resolved their VUR by that visit and may have never had another febrile infection even if not on CAP. It is also possible that children were more prone to UTI after having been on CAP but were randomly assigned to surveillance and therefore taken off CAP on entry.

The National Institutes of Health (NIH), multicenter prospective, randomized placebo controlled study of antibiotic prophylaxis in children, the RIVUR Study (Randomized Intervention for Children with
Vesico-Ureteral Reflux) [20], explored the question of the clinical efficacy of prophylaxis in children with VUR grades 1 to 4 from 2 months to 6 years of age. The 2-year study focused on recurrent febrile UTI (with strict criteria [24]) as the primary endpoint and treatment failure and renal scarring as secondary endpoints. In total, over 300 children were followed in the two arms of active treatment with daily, low-dose trimethoprim-sulfamethoxazole and placebo. At two years, the risk of recurrent febrile UTI was reduced by half in the treatment arm with a hazard ratio of 0.50 (95\% confidence interval 0.34 to 0.74 ), indicating a significant benefit. There was no reduction in new renal scarring, which was at a very low rate in both groups [20]. The benefit of CAP was more pronounced in those children with evidence of bladder dysfunction as well as those who initially presented with a febrile UTI. One concern about the results of this study is that the size of treatment effect is small, reducing the rate of recurrent febrile UTI from about $25 \%$ to $12 \%$. It should be borne in mind that the study population included relatively few patients with grade 4 VUR and a low rate of baseline renal abnormalities. This would suggest a relatively lower risk of VUR complications as compared with the population of, for example, the SRT [18].

Moreover, Figure 1 shows the incidence of UTI during follow-up in these studies whether on CAP or not, as correlated with the incidence of renal damage at initiation of the study. There is an apparent relationship between the presence of baseline renal damage and the risk of UTI off CAP. This clearly suggests potential predictors or determinants of the efficacy of CAP that differs between patients and study populations. Other likely factors to add to this susceptibility may include age, grade of VUR, bladder and bowel dysfunction (BBD), and history of prior UTIs. The benefit of CAP appears greater when the risk of recurrent UTI is higher, which is precisely the situation of concern.

The differences in the results of these studies raise significant questions as to the generalizability of these conclusions and have created significant confusion. With careful examination of these studies, however, the reported variation in results may be understood, and this variation largely reflects different baseline patient populations.

\section{Possible reasons to explain the differences in the data (heterogeneity)}

This heterogeneity of study populations indicates that some patients can be safely managed without CAP but that others are at risk for acute UTI and renal damage and should be treated with CAP. This is consistent with both 


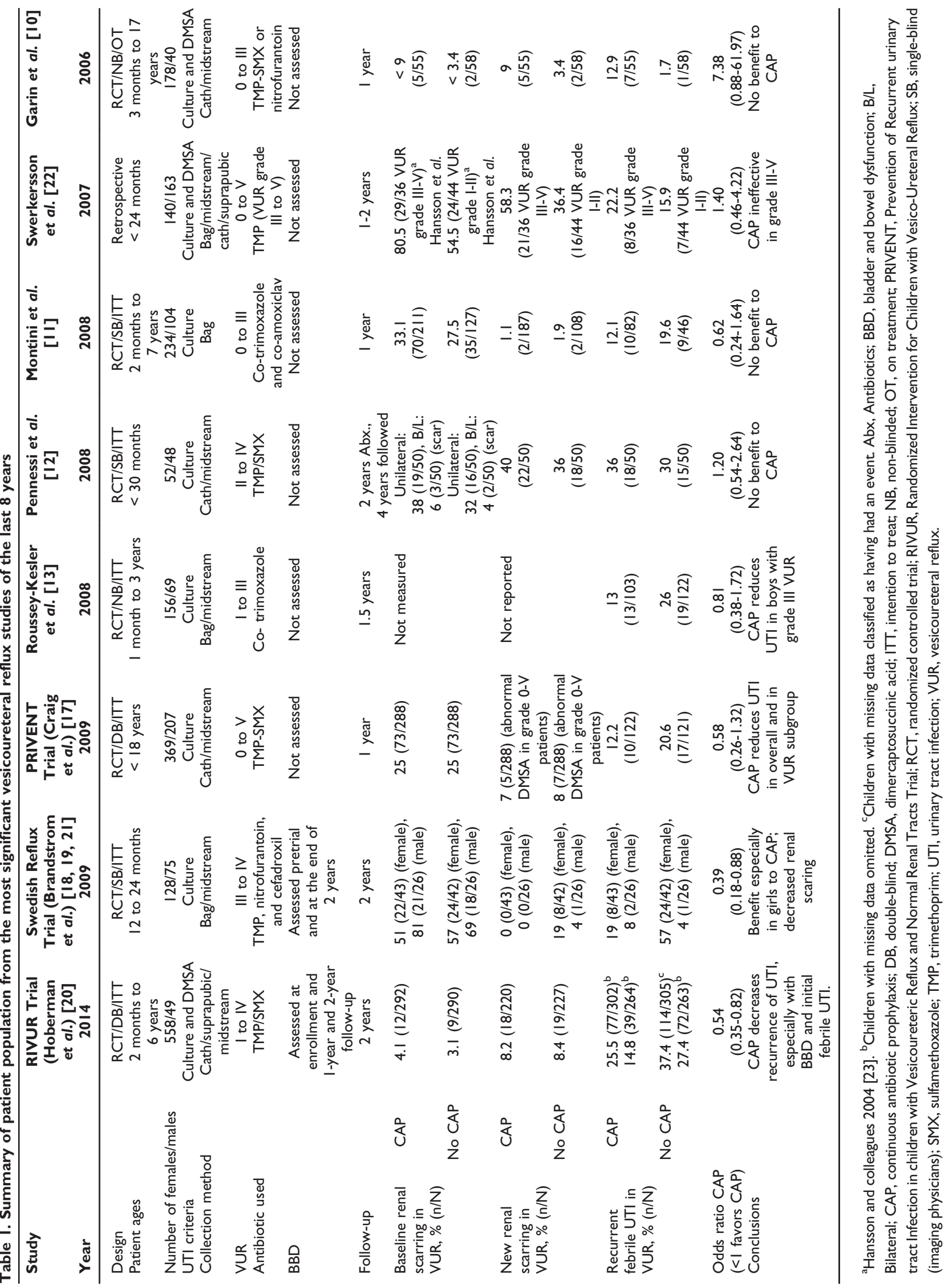


Figure I. Incidence of UTI correlated with rate of baseline renal damage

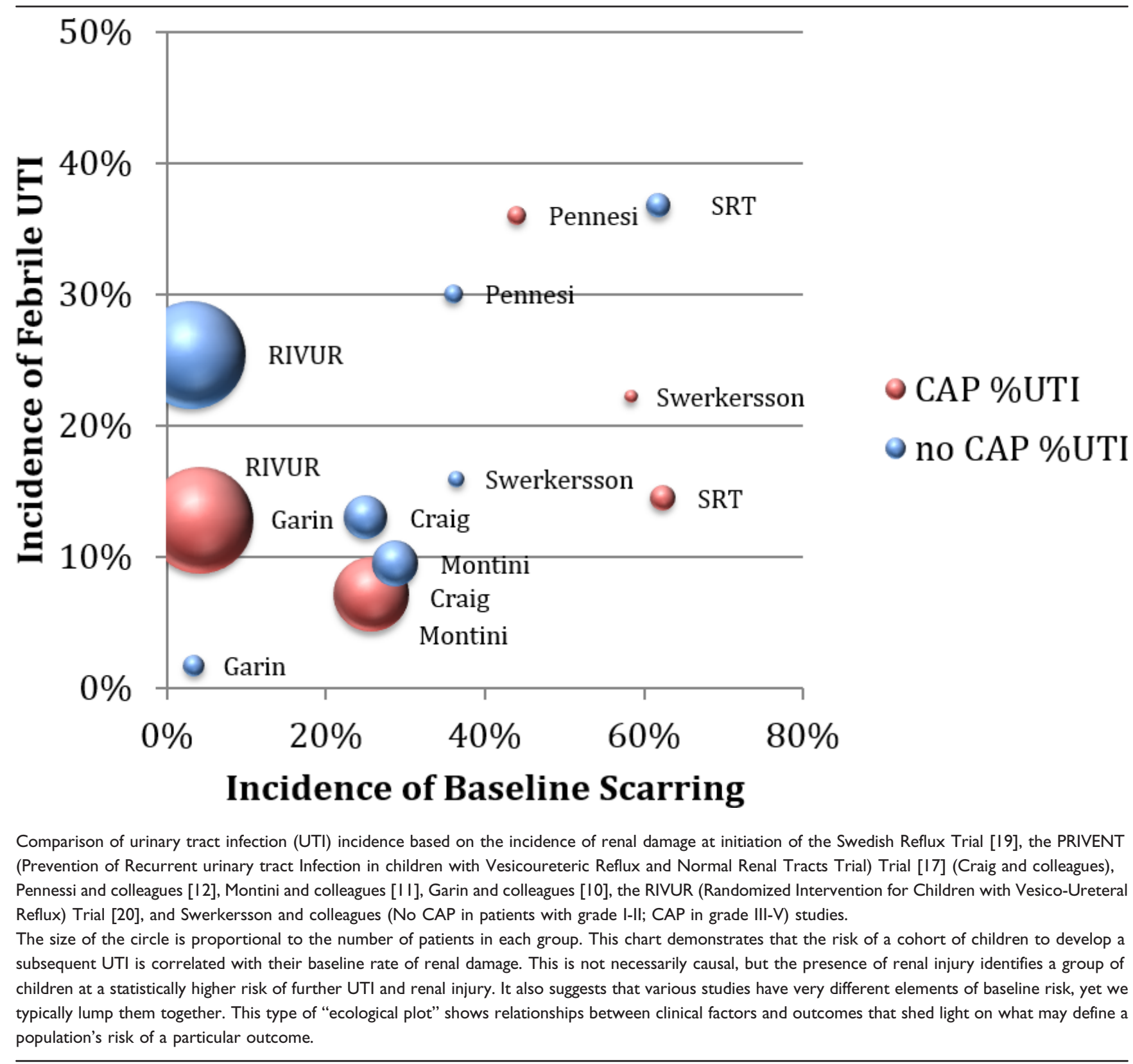

the historical data as well as more recent case series of children being managed safely without CAP.

The results of the SRT and the NIH RIVUR study are not completely inconsistent with the other studies of VUR and CAP, although the RIVUR study is both appropriately powered and controlled, particularly for BBD, whereas many of the other trials were not. Populations with differing risks of subsequent febrile UTI and renal injury will likely have different patterns of response to CAP. In smaller studies, the apparent size and direction of an effect may be different.
The clinical issue is really, what characterizes the child at low risk in contrast to one who should be treated with CAP? Several factors have emerged as likely predictors, even if they cannot be precisely quantified.

\section{Risk models}

In a large health-care system database evaluation, Conway and colleagues [25] examined children with UTI for risk factors of recurrence; age, Caucasian race, and grade IV or V VUR were identified. The study of Dias and colleagues [26] lends support to the concept of risk factors for UTI, although their study assessed 
risk of UTI on CAP and did not attempt to address the risk of UTI without CAP. Using a model of risk for recurrent UTI, they identified female gender, dysfunctional voiding (or BBD), and severe VUR as risk factors for recurrent UTI.

As a component of developing a clinically useful risk model for determining the need for CAP, evidence of renal infection may be useful. This can be shown with an acute DMSA scan at the time of an acute infection. This logic has been used in the so-called "top-down" strategy for selecting patients with febrile UTIs for VCUG but may also be useful as a determinant of the possible value of CAP [27].

Several studies have suggested that procalcitonin may be a reliable biomarker that predicts renal parenchymal involvement and high-grade VUR in children with a first UTI $[26,28]$. Procalcitonin levels may offer a better guide to the need for DMSA scans and the decision to use CAP in VUR when taken into consideration with the clinical history $[29,30]$.

It should be recognized that with current data, there is no certain predictor of risk of acute UTI or renal damage, and even when better data are obtained, it will not likely be a clear "yes or no" answer, but shades of gray. At the same time, these observations permit the development of a clinical approach to children with VUR in whom medical therapy is considered. The child likely to have little need for CAP is the one with a low risk of UTI, with a limited history of infection (or no prior infection), normal voiding habits, no evidence of renal scarring, and lower grades of VUR. It is currently unrealistic to ask for a simple cutoff level of reflux (Figure 2). Clear indicators for using CAP would be multiple prior UTIs, renal scarring, dilating reflux (grades III to V), and abnormal voiding. Added to this must be social factors as well as parental preferences and attitudes. The parents of a child who may have originally presented with severe pyelonephritis are seldom willing to risk this recurrence. This must be factored into the longer-term likelihood of reflux resolution in the at-risk child. The older child with high-grade VUR may be much less likely to resolve their VUR and may be best managed with a curative intervention. The debate regarding endoscopic or surgical methods cannot be addressed here, but the risk of reflux recurrence after endoscopic treatment must be a factor in this balance. The presence of $\mathrm{BBD}$, a strong reason to use CAP, should prompt aggressive therapy and avoidance of surgery if possible. Only if recurrent infections occur while working to improve BBD should surgery be a strong recommendation. Endoscopic therapy for VUR in the face of BBD has been shown to be less effective [31,32].

\section{Alternatives to continuous antibiotic prophylaxis in vesicoureteral reflux} Intermittent therapy for urinary tract infection and reflux An alternative to CAP when managing children with VUR is the use of antibiotics as intermittent therapy, active surveillance, and rapid treatment of UTI. The intermittent therapy approach has had limited study and, certainly in the SRT, was shown to allow more renal damage than CAP in that population [21]. Several significant assumptions underlie using this approach. The first is that any new UTI will be rapidly recognized and treated. This assumes a clear clinical presentation with voiding symptoms or fever, which is not always the case, and is less reliable in younger patients. Not all children with pyelonephritis have fever, and they may not have lower tract symptoms. Coulthard and colleagues [33] published a concerning report that attempts to assess the ability to identify UTI in an at-risk population. The assumption is often made that older children will be able to report symptoms more promptly and thereby permit treatment, yet the report showed a greater delay in treatment in the older patients and development of new renal scars. Symptoms were not always predictive of UTI or new renal scarring. This treatment approach also assumes ready access to evaluation and treatment. For some families, this is simply not feasible, because of geography or social situation.

\section{Stopping continuous antibiotic prophylaxis}

As the utility of CAP for VUR was questioned, several reports of children with VUR managed without antibiotics after a period of treatment with prophylaxis were published. These were all case series, were without controls, and had limited follow-up [8,9,34-36]. Clinical follow-up with some imaging assessment, but often only ultrasound, was used to define outcomes. These were highly selected patients rather than a broad population. They were, in essence, self-selected to a large degree in that they had not had problems with breakthrough UTI or overt renal injury. Although it is tempting to generalize these conclusions to all patients with reflux, this may be an over-interpretation of the results [37]. The key conclusions to these studies should really be seen as demonstrating that some children with VUR can be safely managed without CAP. Our challenge then becomes developing a means by which these children can be identified prospectively.

A further concern when no CAP is administered is what to do in case of a new febrile illness or symptomatic UTI. Ideally, every febrile episode should be fully evaluated for a UTI in children with VUR. Early recognition of a new UTI episode is essential in order for it to be appropriately treated and to prevent new renal damage [33]. This regimen requires a significant commitment 
Figure 2. Patient profiles for risk of urinary tract infection

\section{Risk of UTI}

\begin{tabular}{|c|c|c|c|}
\hline & Low & & High \\
\hline Grade & II & $\Delta$ & $\mathrm{v}$ \\
\hline BBBD & Mild & Moderate & Severe \\
\hline Age & School Age & Toddler & Infant \\
\hline$\underline{\text { Sex }}$ & Male (circumcised) & (uncircumcised) & male \\
\hline Infections & None & Few & \\
\hline Scarring & None & Moderate & \\
\hline
\end{tabular}

\section{Risk of UTI}

\begin{tabular}{|c|c|c|c|}
\hline & Low & & High \\
\hline Grade & & 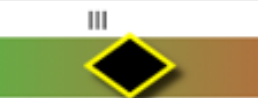 & v \\
\hline BBD & Mid & Moderate & Severe \\
\hline Age & & Todder & Intant \\
\hline Sex & & (uncircumcised) & $\begin{array}{c}\text { Female } \\
\end{array}$ \\
\hline Infections & & Few & Recurrent \\
\hline Scarring & & Moderate & Severe \\
\hline
\end{tabular}

Management of these children should be specific to their risk profile rather than simply the grade of reflux. 
from the parents as well as from the primary care provider. It is therefore essential to educate parents and caregivers, according to their level of health literacy, regarding the importance of having a high degree of suspicion to ensure that appropriate action be taken. It is also important for the physician to recognize whether such a regimen is appropriate for a particular family, considering factors such as medical awareness, access to health care, and lines of communication with family and caregivers.

\section{Guidelines}

Guidelines are often confusing to practitioners who see them as proscriptive in terms of patient care. Our view is that they provide a framework, hopefully based on solid data, within which appropriate patient care can be defined. Any experienced clinician will recognize that no two patients are exactly alike, and the importance of perceiving the relevant differences is critical. Guidelines should not be an instrument of policy nor an excuse for turning off one's brain. Nonetheless, we cannot ignore the thought and care that have gone into them, and we recognize their distinctive perspectives and the impact that can have on their guidance.

\section{American Urological Association guidelines for vesicoureteral reflux}

In recognition of the recent challenges to the utility and safety of CAP, the 2010 AUA Clinical Guidelines for managing VUR have included an option of not using CAP in selected children. The criteria for use of this approach include children less than 1 year and with grade I or II VUR, no history of febrile UTI, and no renal cortical abnormalities. For children over 1 year, no CAP is an option for those without history of febrile UTI, no history of BBD, and no renal cortical abnormalities. The term "option" is recognition that there is no strong evidence to support one approach over another and that both would be considered appropriate [31].

\section{National Institute for Health and Care Excellence guidelines}

The National Health Service in the UK, through the National Institute for Health and Care Excellence, has published a set of guidelines aimed at the evaluation and management of the child with a UTI [38]. These guidelines have several elements in common with the American Academy of Pediatrics (AAP) UTI guidelines and focus on stratifying the severity of the infection and tailoring subsequent evaluation to that stratification. The severity of illness, age, and prior history of UTIs are the critical factors in this determination. Only younger children with evidence of upper tract infection are recommended to have any initial imaging, and that is limited to a renal ultrasound. VCUG is recommended only in children under 6 months with an atypical UTI, which includes findings of sepsis, mass, elevated creatinine, poor urine flow, or failure to respond to appropriate antibiotics within 48 hours, recurrent UTI, or non-Escherichia coli infection. DMSA is recommended to assess the renal parenchyma prior to a VCUG in many situations with older children. These guidelines are reasonable in many ways, but it must be recognized that a certain number of children will have preventable febrile UTIs and renal scarring. The magnitude of that number, its clinical impact, and effect on the child are undefined. It is also uncertain whether this level of missed prevention is acceptable.

Response to the guidelines has shown reduction in the number of VCUGs; however, the use of DMSA has increased [39]. Several studies have shown a significant rate of patients with missed dilating and high-grade VUR, many of whom were referred to surgery $[40,41]$. As before, the critical determination is to define an acceptable level of safety in terms of balancing costs, radiation, and invasiveness with the potential value to protect children against recurrent UTI. With the value of prophylactic antibiotics in the setting of VUR being demonstrated with the RIVUR trial, this balance may fall more in favor of diagnosing VUR more aggressively.

\section{American Academy of Pediatrics guidelines for diagnosis and management of febrile urinary tract infection in infants under 2 years of age}

The AAP subcommittee on UTI recently published new guidelines for the diagnosis and evaluation of febrile UTI in children less than 2 years of age [16]. Although several important clarifications in regard to appropriate diagnosis and therapy for UTI have been included, a major change has been the action statement that a routine VCUG is no longer recommended after an initial febrile UTI if a renal ultrasound is normal. This conclusion was based on a meta-analysis of the several studies discussed above that could not prove a benefit to using CAP for patients with VUR. As a result, the committee felt that making the diagnosis of VUR was not justified if CAP was not an effective therapy. They also cited reports that renal scarring could occur in the absence of VUR. This represents a recommendation for significant change in managing children with febrile UTI, and the implications remain undefined.

Based on the discussion above, several concerns can be raised, including the validity of generalizing the results from these studies to all patients and more specifically to those under the age of 2 . The risk of further renal injury has been documented with subsequent UTIs, and the 
recommendation of the AAP assumes rapid treatment, which may not always be the case. This concern may be more important in underserved communities as also noted above. Formal responses to the AAP Guideline have been published and this issue continues to be debated $[42,43]$. The impact of the new data from the RIVUR Study remains to be determined. At present, it seems prudent to individualize decisions regarding evaluation of children with febrile UTIs until more specific indicators of risk are available.

\section{Research}

The areas in which we need to focus our research efforts and resources fall into three categories. One is biomarkers of both upper tract infectious injury as well as susceptibility. It is clear that not all children with pyelonephritis will develop a scar, but it is not at all clear why one child will and another will not. Is this a trait we could identify to guide risk assessment? A second area is in creating tools for the better clinical assessment of children with infections, particularly in the arena of bladder and bowel function and dysfunction. These are well-recognized key factors, yet we are very poor at assessing their clinical impact. A third important area is to define globally acceptable levels of risk prevention. What is an acceptable number of children to be missed in terms of their reflux? Although 5\% has been a traditional number, if that is your child who is injured because of less aggressive investigation or too aggressive an investigation, the 5\% number is hardly a comfort. A common vocabulary for risk and risk perception needs to be developed and used in these discussions and guidelines.

\section{Summary}

Antibiotic prophylaxis has been shown to be effective in preventing UTI in some children with VUR but is not required for all. Although strict criteria for the identification of those who are best managed with CAP have yet to be defined, there is evidence to guide us today. Children with a clear history of recurrent UTI should be offered $\mathrm{CAP}$ and monitoring. If they continue to have breakthrough UTI, alternative approaches, such as surgical intervention, need to be considered. The child with documented renal abnormalities on US or DMSA scanning should be offered CAP as they have shown a higher risk of further injury and they have less renal reserve. The child with abnormal voiding patterns or BBD should be offered CAP while an attempt is made to correct his or her voiding patterns. Although most BBD is evident after toilet training, careful questioning of parents may reveal voiding abnormalities in the infant as well. Parental understanding of the risks of renal injury from infection must be clear. If CAP is to be used, the obligation of education is equally strong in that failure to follow the medication program may lead to a false sense of security among both parents and caregivers. The precision of these criteria is obviously limited, but they can serve as a means by which clinical decisions may be made and revised. As the child grows, if VUR persists, the option of discontinuing CAP becomes more attractive, and the information regarding the patient's risk of UTI improves, based on their clinical patterns.

It is very clear that management of VUR cannot be based simply on VUR grade or broad statements of the utility of $\mathrm{CAP}$, but must be individualized. The basis for CAP rests in the clinical experience from four decades ago, when many more children suffered from acute febrile UTI and developed significant renal injury. Therefore, it is prudent to consider UTIs not only as acute episodes of illness but also as a first step to possible renal damage. In carefully conducted studies, its utility in preventing UTI has been demonstrated.

These data should not be interpreted to indicate that all children with VUR must be treated with CAP, just as it is not supported that no child with VUR should be treated with CAP. All of the recent data examining the role of CAP point broadly in the direction that we need to identify subsets of children with differential risk for VUR complications of recurrent febrile UTI and renal injury. Although it is not possible to define these risk groups with a formula, more robust data should ultimately permit increasingly precise risk stratification and selective therapy.

\section{Abbreviations}

AAP, American Academy of Pediatrics; AUA, American Urological Association; BBD, bladder and bowel dysfunction; CAP, continuous antibiotic prophylaxis; DMSA, dimercaptosuccinic acid; NIH, National Institutes of Health; RIVUR, Randomized Intervention for Children with Vesico-Ureteral Reflux; SRT, Swedish Reflux Trial; UTI, urinary tract infection; VCUG, voiding cystourethrogram; VUR, vesicoureteral reflux.

\section{Disclosures}

The authors declare that they have no disclosures.

\section{References}

I. Normand IC, Smellie JM: Prolonged Maintenance Chemotherapy in the Management of Urinary Infection in Childhood. BM] $1965, \mathrm{I}: 1023-6$.

FlOOOPrime RECOMMENDED

2. Elder JS, Peters CA, Arant BS, Jr., Ewalt DH, Hawtrey CE, Hurwitz RS, Parrott TS, Snyder HM 3rd, Weiss RA, Woolf SH, Hasselblad V: Pediatric Vesicoureteral Reflux Guidelines Panel summary report on the management of primary vesicoureteral reflux in children. J Urol 1997, I57:|846-5I. 
3. Smellie JM, Normand IC: Bacteriuria, reflux, and renal scarring. Arch Dis Child 1975, 50:581-5.

\section{FIOOOPrime}

4. Arant BS, Jr.: Medical management of mild and moderate vesicoureteral reflux: followup studies of infants and young children. A preliminary report of the Southwest Pediatric Nephrology Study Group. J Urol 1992, I48:|683-7.

5. Birmingham RSG: Prospective trial of operative versus nonoperative treatment of severe vesicoureteric reflux in children: five years' observation. Birmingham Reflux Study Group. BMJ 1987, 295:237-4I.

6. Jodal U, Smellie JM, Lax H, Valenciano B, Campos A, Young L: Ten-year results of randomized treatment of children with severe vesicoureteral reflux. Final report of the International Reflux Study in Children. Pediatr Nephrol 2006, $21: 785-92$.

7. Elder JS: Commentary: importance of antenatal diagnosis of vesicoureteral reflux. J Urol 1992, I48:1750-4.

8. Cooper CS, Chung BI, Kirsch AJ, Canning DA, Snyder HM 3rd.: The outcome of stopping prophylactic antibiotics in older children with vesicoureteral reflux. J Urol 2000, 163:269-72; discussion 272-63.

9. Thompson RH, Chen JJ, Pugach J, Naseer S, Steinhardt GF: Cessation of prophylactic antibiotics for managing persistent vesicoureteral reflux. J Urol 200 I, I66:1465-9.

10. Garin EH, Olavarria F, Garcia Nieto V, Valenciano B, Campos A, Young L: Clinical significance of primary vesicoureteral reflux and urinary antibiotic prophylaxis after acute pyelonephritis: a multicenter, randomized, controlled study. Pediatrics 2006, | | 7:626-32.

\section{FIOOOPrime
RECOMMENDED}

I I. Montini G, Rigon L, Zucchetta P, Fregonese F, Toffolo A, Gobber D, Cecchin D, Pavanello L, Molinari PP, Maschio F, Zanchetta S, Cassar W, Casadio L, Crivellaro C, Fortunati P, Corsini A, Calderan A, Comacchio S, Tommasi L, Hewitt IK, Da Dalt L, Zacchello G, Dall'Amico R IRIS Group: Prophylaxis After First Febrile Urinary Tract Infection in Children? A Multicenter, Randomized, Controlled, Noninferiority Trial. Pediatrics 2008, | 22: |064-7|.

12. Pennesi M, Travan L, Peratoner L, Bordugo A, Cattaneo A, Ronfani L, Minisini S, Ventura A, North East Italy Prophylaxis in VUR study group: Is antibiotic prophylaxis in children with vesicoureteral reflux effective in preventing pyelonephritis and renal scars? A randomized, controlled trial. Pediatrics 2008, I 2 I :el489-94.

\section{FlOOOPrime}

\section{RECOMMENDED}

13. Roussey-Kesler G, Gadjos V, Idres N, Horen B, Ichay L, Leclair MD, Raymond F, Grellier A, Hazart I, de Parscau L, Salomon R, Champion G, Leroy V, Guigonis V, Siret D, Palcoux JB, Taque S, Lemoigne A, Nguyen JM, Guyot C: Antibiotic prophylaxis for the prevention of recurrent urinary tract infection in children with low grade vesicoureteral reflux: results from a prospective randomized study. J Urol 2008, I79:674-9; discussion 679.

\section{FlOOOPrime
RECOMMENDED}

14. Lackgren G, Skoldenberg E, Stenberg A: Endoscopic treatment with stabilized nonanimal hyaluronic acid/dextranomer gel is effective in vesicoureteral reflux associated with bladder dysfunction. J Urol 2007, I 77: I I 24-8; discussion I I 28-9.

\section{FlOOOPrime}

\section{RECOMMENDED}

15. National Collaborating Centre for Women's and Children's Health (UK): Urinary Tract Infection in Children - diagnosis, treatment and longterm management. London: Royal College of Obstetricians and Gynaecologists Press; 2007.
16. Roberts KB: Urinary tract infection: clinical practice guideline for the diagnosis and management of the initial UTI in febrile infants and children 2 to 24 months. Pediatrics 20I I, I 28:595-6I 0 .

\section{FlOOOPrime}

\section{RECOMMENDED}

17. Craig JC, Simpson JM, Williams GJ, Lowe A, Reynolds G], McTaggart SJ, Hodson EM, Carapetis JR, Cranswick NE, Smith G, Irwig LM, Caldwell PH, Hamilton S, Roy LP, Prevention of Recurrent Urinary Tract Infection in Children with Vesicoureteric Reflux and Normal Renal Tracts (PRIVENT) Investigators. Antibiotic prophylaxis and recurrent urinary tract infection in children. $N$ Engl J Med 2009, $36 \mathrm{I}:$ I 748-59.

\section{FIOOOPrime
RECOMMENDED}

18. Brandstrom P, Esbjorner E, Herthelius M, Holmdahl G, Läckgren G, Nevéus T, Sillén U, Sixt R, Sjöberg I, Stokland E, Jodal U, Hansson S: The Swedish reflux trial in children: I. Study design and study population characteristics. J Urol 2010, 184:274-9.

\section{FlOOOPrime}

RECOMMENDED

19. Brandstrom P, Esbjorner E, Herthelius $M$, Swerkersson S, Jodal U, Hansson S: The Swedish reflux trial in children: III. Urinary tract infection pattern. J Urol 2010, I84:286-91.

\section{FlOOOPrime}

RECOMMENDED

20. RIVUR Trial Investigators: Antimicrobial Prophylaxis for Children with Vesicoureteral Reflux. N EnglJ Med 20I4, 370:2367-76.

\section{FlOOOPrime}

21. Brandstrom P, Neveus T, Sixt R, Stokland E, Jodal U, Hansson S: The Swedish reflux trial in children: IV. Renal damage. J Urol 2010 , I 84:292-7.

\section{FlOOOPrime \\ RECOMMENDED}

22. Swerkersson S, Jodal U, Sixt R, Stokland E, Hansson S: Relationship among vesicoureteral reflux, urinary tract infection and renal damage in children. J Urol 2007, I78:647-5 I.

23. Hansson S, Dhamey M, Sigstrom O, Sixt R, Stokland E, Wennerstrom $M$, Jodal U: Dimercapto-succinic acid scintigraphy instead of voiding cystourethrography for infants with urinary tract infection. J Urol 2004, I72:107|-3.

24. Keren R, Carpenter MA, Hoberman A, Shaikh N, Matoo TK, Chesney RW, Matthews R, Gerson AC, Greenfield SP, Fivush B, McLurie GA, Rushton HG, Canning D, Nelson CP, Greenbaum L, Bukowski T, Primack W, Sutherland R, Hosking J, Stewart D, Elder J, Moxey-Mims M, Nyberg L: Rationale and design issues of the Randomized Intervention for Children With Vesicoureteral Reflux (RIVUR) study. Pediatrics 2008, I 22(Suppl 5):S240-50.

25. Conway PH, Cnaan A, Zaoutis T, Henry BV, Grundmeier RW, Keren $\mathrm{R}$ : Recurrent urinary tract infections in children: risk factors and association with prophylactic antimicrobials. JAMA 2007, 298: $179-86$

26. Dias CS, Silva JM, Diniz JS, Lima EM, Marciano RC, Lana LG, Trivelato AL, Lima MS, Simöes e Silva AC, Oliveira EA: Risk factors for recurrent urinary tract infections in a cohort of patients with primary vesicoureteral reflux. Pediatr Infect Dis J 2010, 29: 139-44.

\section{FlOOOPrime}

\section{RECOMMENDED}

27. Pohl HG, Belman AB: The "top-down" approach to the evaluation of children with febrile urinary tract infection. Adv Urol 2009, 783409.

\section{FlOOOPrime}

RECOMMENDED

28. Leroy S, Romanello C, Galetto-Lacour A, Smolkin V, Korczowski B, Rodrigo C, Tuerlinckx D, Gajdos V, Moulin F, Contardo M, Gervaix A, Halevy R, Duhl B, Prat C, Borght TV, Foix-l'Hélias L, Dubos F, 
Gendrel D, Bréart G, Chalumeau M: Procalcitonin to reduce the number of unnecessary cystographies in children with a urinary tract infection: a European validation study. J Pediatr 2007, 150:89-95.

\section{FlOOOPrime}

\section{RECOMMENDED}

29. Leroy S, Bouissou F, Fernandez-Lopez A, Gurgoze MK, Karavanaki K, Ulinski T, Bressan S, Vaos G, Leblond P, Coulais Y, Cubells CL, Aygun AD, Stefanidis CJ, Bensman A, Da Dalt L, Gardikis S, Bigot S, Gendrel D, Bréart G, Chalumeau M: Prediction of high-grade vesicoureteral reflux after pediatric urinary tract infection: external validation study of procalcitonin-based decision rule. PLoS One 20II, 6:e29556.

\section{FlOOOPrime} RECOMMENDED

30. Liao PF, Ku MS, Tsai JD, Choa YH, Hung TW, Lue KH, Sheu JN: Comparison of procalcitonin and different guidelines for first febrile urinary tract infection in children by imaging. Pediatr Nephrol 20I4, 29:1567-74.

\section{FlOOOPrime

RECOMMENDED

31. Peters CA, Skoog SJ, Arant BS, Jr., Copp HL, Elder JS, Hudson RG, Khoury AE, Lorenzo AJ, Pohl HG, Shapiro E, Snodgrass WT, Diaz M: Summary of the AUA Guideline on Management of Primary Vesicoureteral Reflux in Children. J Urol 2010, 184: I I34-44.

32. Sedberry-Ross S, Rice DC, Pohl HG, Belman AB, Majd M, Rushton HG: Febrile urinary tract infections in children with an early negative voiding cystourethrogram after treatment of vesicoureteral reflux with dextranomer/hyaluronic acid. J Urol 2008, 180:1605-9; discussion 1610.

\section{FlOOOPrime}

\section{RECOMMENDED}

33. Coulthard MG, Verber I, Jani JC, Lawson GR, Stuart CA, Sharma V, Lamb WH, Keir MJ: Can prompt treatment of childhood UTI prevent kidney scarring? Pediatr Nephrol 2009, 24:2059-63.

\section{FlOOOPrime}

\section{RECOMMENDED}

34. Al-Sayyad AJ, Pike JG, Leonard MP: Can prophylactic antibiotics safely be discontinued in children with vesicoureteral reflux? J Urol 2005, 174: 1587-9; discussion I589.

35. Alconcher LF, Meneguzzi MB, Buschiazzo R, Piaggio LA: Could prophylactic antibiotics be stopped in patients with history of vesicoureteral reflux? J Pediatr Urol 2009, 5:383-8.
36. Leslie B, Moore K, Salle JL, Khoury AE, Cook A, Braga LH, Bägli DJ, Lorenzo AJ: Outcome of antibiotic prophylaxis discontinuation in patients with persistent vesicoureteral reflux initially presenting with febrile urinary tract infection: time to event analysis. J Urol 2010, 184:1093-8.

\section{FlOOOPrime}

RECOMMENDED

37. Drzewiecki BA, Thomas JC, Pope JC 4th, Adams MC, Brock JW 3rd, Tanaka ST: Observation of patients with vesicoureteral reflux off antibiotic prophylaxis: physician bias on patient selection and risk factors for recurrent febrile urinary tract infection. J Urol 20I2, 188:1480-4.

38. Urinary tract infection in children: Diagnosis, treatment and long-term management. National Institute for Health and Care Excellence (NICE). 2007, [http://www.nice.org.uk/guidance/CG54/ chapter/I-Guidance]

39. Judkins A, Pascoe E, Payne D: Management of urinary tract infection in a tertiary children's hospital before and after publication of the NICE guidelines. Arch Dis Child 20I3, 98:52I-5.

\section{FlOOOPrime}

\section{RECOMMENDED}

40. Lytzen R, Thorup J, Cortes D: Experience with the NICE guidelines for imaging studies in children with first pyelonephritis. Eur J Pediatr Surg 201 I, 21:283-6.

\section{FlOOOPrime}

RECOMMENDED

4I. Ristola MT, Hurme T: NICE Guidelines Cannot Be Recommended for Imaging Studies in Children Younger Than 3 Years with Urinary Tract Infection. EurJ Pediatr Surg 20 14, [Epub ahead of print].

\section{FlOOOPrime}

RECOMMENDED

42. Roberts KB, Finnell SM, Downs SM: Response to the AAP section on urology concerns about the AAP urinary tract infection guideline. Pediatrics 2012, I29:e I054-6.

43. Wan J, Skoog SJ, Hulbert WC, Casale AJ, Greenfield SP, Cheng EY, Peters CA, Executive Committee, Section on Urology, American Academy of Pediatrics: Section on Urology Response to New Guidelines for the Diagnosis and Management of UTI. Pediatrics 2012, I29:el05I-3. 